\title{
An Uncommon Cause of Abdominal Mass: Phytobezoar
}

\section{Dibas Khadka, Binod Karki, Suresh Thapa and Barun Shrestha}

National Academy of Medical Sciences, Bir Hospital, Kathmandu, Nepal

\begin{abstract}
Phytobezoar is a gastric foreign body formed due to accumulation of ingested fruits and/or vegetables. Patients usually have a predisposing condition leading to alteration in gastric emptying. Altered gastric emptying leads to stagnation and amalgamation of the ingested vegetables or fruits. This condition can be easily diagnosed with upper gastrointestinal endoscopy. Management is medical if the size is small. Larger phytobezoars need endoscopic therapy. In this case report, we describe a case of phytobezoar in a middle aged lady with no known risk factor. She was managed successfully by therapeutic endoscopy.
\end{abstract}

Keywords: gastic bezoar; phytobezoar; abdminal mass; Nepal

Correspondence: Dibas Khadka, National Academy of Medical Sciences, Bir Hospital, Kathmandu, Nepal Email : dibask@gmail.com

To cite this article: Khadka D, Karki B, Thapa S, Shrestha B. An Uncommon Cause of Abdominal Mass: Phytobezoar. Medical Journal of Shree Birendra Hospital. 2017;17(2):69-73

DOI: http://dx.doi.org/10.3126/mjsbh.v16i2.17891

Conflict of Interest: None declared

\section{INTRODUCTION}

Gastric bezoar is a foreign body formed due to accumulation of the ingested material. It is commonly found as hard mass or concretion in the stomach.

Gastric bezoar either presents with wide variety of nonspecific abdominal complains or may be detected incidentally during endoscopy or imaging. A study involving 1400 gastroscopies found an incidence of Gastric Bezoars to be $0.3 \% .^{1}$ It is more common in men in the age group 40-50 years ${ }^{2}$. Risk factor for gastric bezoar include history of gastric surgery, gastroparesis, gastric outlet obstruction, anti cholinergic agents, opiates, dehydration. ${ }^{3-5}$

We report a case of phytobezoar who had presented with complains of abdominal pain, non-significant weight loss and occasional vomiting. 


\section{CASE REPORT}

A 52 years housewife from far western region of Nepal presented to our Gastroenterology OPD with complains of upper abdominal pain for one year. Pain was dull, continuous, associated with early satiety and occasional vomiting. She also reported non-significant weight loss in last one year. Pain was not related with meals or defecation, and nonradiating. There was no history of fever and she denied any change in bowel habit or blood in stools. There was no significant past medical or surgical history. There was no history of chronic alcohol abuse. Clinical examination revealed 4 X 8 $\mathrm{cm}$ firm, non tender and mobile mass in the left upper quadrant of abdomen. She was admitted for evaluation. Her complete blood counts, random blood glucose, renal function test, liver function test were all within normal limits. Ultrasonography and Contrast Enhanced CT of abdomen and pelvis was unremarkable. Upper Gastrointestinal Endoscopy (UGIE) revealed a mobile green foreign body of approximate size $3 \mathrm{~cm} \mathrm{X} 8 \mathrm{~cm}$ extending from body to antrum of the stomach (Figure 1). Foreign body was examined by biopsy forceps. On biting with biopsy forceps filamentous parts were extracted from the foreign body. Endoscope could be negotiated beyond the foreign body up to the second part of duodenum. The mucosal surface under the foreign body was erythematous and rest of the endoscopic examination was normal. Patient was diagnosed to have phytobezoar. She was put on oral metoclopramide and Coca cola 3 litres per day. However patient could take only about one litre of Coca cola because of abdominal discomfort. After one week UGIE was repeated. UGIE showed findings similar to last endoscopy. The phytobezoar was disintegrated by the use of endoscope, snare forceps, biopsy forceps and injection normal saline into the lesion by sclerotherapy needle. Strands of

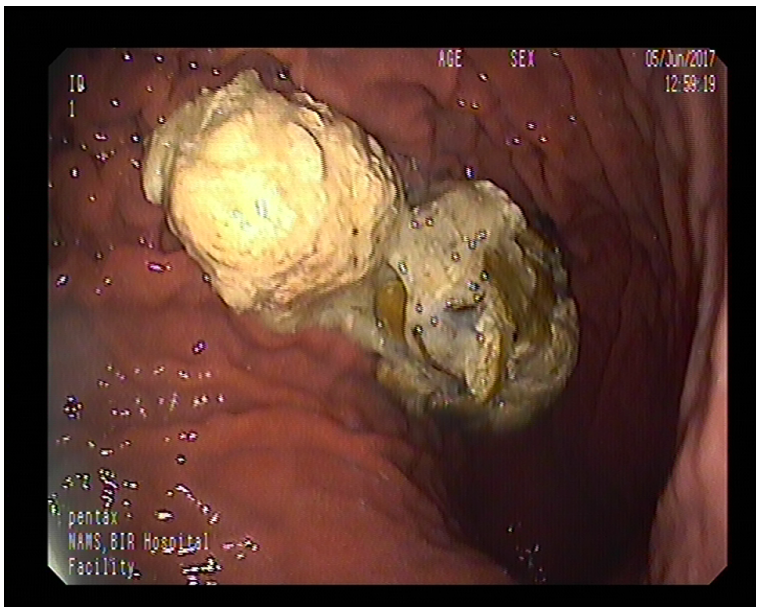

Figure 1: Endoscopic view of Phytobezoar. Strands of vegetables are seen.

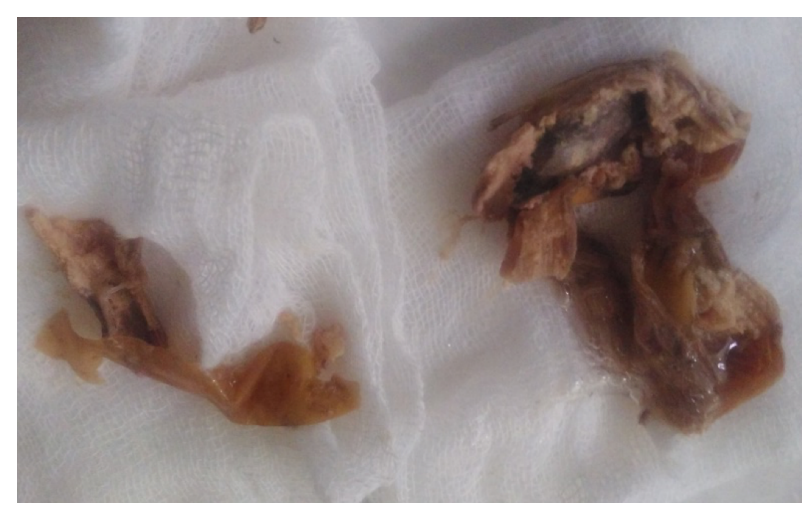

Figure 2: Strands of putrefied vegetables extracted using snare forceps

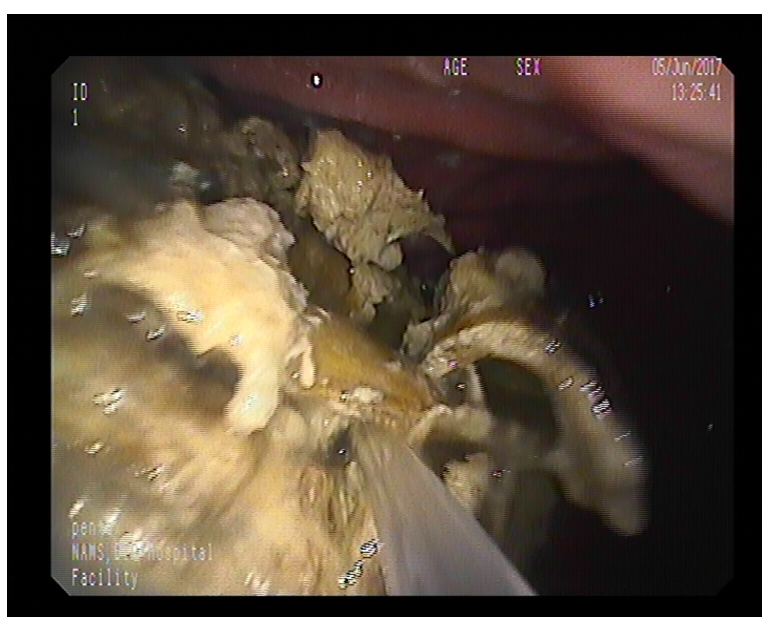

Figure 3:Endoscopic fragmentation of phytobezoar. 
vegetables were extracted by snare forceps, as shown in figure 2. After 30 minutes of endoscopic therapy, major portion of phytobezoar was disintegrated and mass had been divided into two smaller parts. After 3 days UGIE was repeated and it confirmed clearance of mass. Patient had resolution of her symptoms. Abdominal mass had disappeared and she was discharged with plan to perform Gastric Emptying test if symptoms of gastroparesis occurred.

\section{DISCUSSION AND REVIEW OF LITERATURE}

Gastric bezoar is a rare condition and is considered as a differential diagnosis in many other gastrointestinal diseases. There are four types of Gastric Bezoarss:-

1. Phytobezoars- commonest and composed of vegetable matters

2. Trichobezoars- composed of hairs

3. Pharmacobezoars-composed of medications

4. Other- composed of wide variety if substances. Example styrofoam, cement, tissue paper etc.

Gastric bezoars can have multiple presentation. Bezoars are formed from ingestion of indigestible material in patients with impairment in the gastric motility. ${ }^{5}$ Phytobezoars are the commonest type of gastric bezoar. Commonly implicated fruits and vegetables include celery, pumpkin, prunes, raisins, leeks, beets, and persimmon.7 Phytobezoars form when food containing large amounts of insoluble and indigestible fibers such as cellulose, hemicellulose, lignin, and fruit tannin are ingested and accumulated. ${ }^{8}$ Majority of patients with bezoars (other than trichobezoars) have a risk factor that delays emptying of gastric contents. Patients may be asymptomatic but majority of cases $(80 \%)$ complains of vague epigastric discomfort. ${ }^{9}$
Anorexia, nausea, vomiting, weight loss, and early satiety may also be present. Bezoars can cause gastric ulceration secondary to pressure necrosis. Bezoar-induced gastric ulcers can cause bleeding and gastric outlet obstruction. ${ }^{6}$ History can be helpful in diagnosis. Note should be made of previous bezoar, gastric surgery, or gastric dysmotility. Physical examination occasionally detect a palpable abdominal mass. Halitosis may be present because of putrefying materials of the bezoar residing in the stomach. Plain abdominal radiograph may demonstrate the outline of the bezoar. On contrast radiography, a gastric bezoar classically presents as filling defects within the stomach. Gastric bezoars are definitively diagnosed with upper endoscopy; phytobezoars appear as a dark brown, green, or black mass of amorphous vegetable material in the stomach. Small bezoars are treated conservatively with liquid diet for a short period of time and a prokinetic agent to promote gastric emptying. For those not responding to conservative therapy chemical dissolution, endoscopic removal or surgery may be required. Chemical dissolution agents include Coca-cola, Cellulase, Papain and Acetylcysteine. Coca-cola is administered via gastric lavage $(3000 \mathrm{~mL}$ over a 12-hour period) or consumed same amount by patients without nausea or vomiting. Coca-Cola's action may be attributed to its low $\mathrm{pH}$, the mucolytic effect of its high sodium bicarbonate content, and the $\mathrm{CO} 2$ bubbles which enhance dissolution. A systematic review of 24 observational studies that included 46 patients, showed that administration of Coca-Cola alone resulted in resolution of phytobezoars in 23 (50 percent) patients. In 23 patients with partial dissolution with Coca-Cola, concomitant endoscopic therapy resulted in dissolution in 19 patients and only 4 patients required surgery. ${ }^{10}$ 
Cellulase tablets or solutions disintegrates the cellulose and hemicellulose found in plant fiber and phytobezoars. Reported success rates range from 83 to 100 percent. ${ }^{11-12}$ Papain administered in the form of Adolph's Meat Tenderizer, 1 teaspoon in $120 \mathrm{~mL}$ of water before each meal or papase two $(10,000$ unit) tablets with each meal. ${ }^{13}$ Acetylcysteine has been administered via nasogastric tube $(15 \mathrm{~mL}$ of acetylcysteine in $50 \mathrm{~mL}$ of water, twice daily) and endoscopically $(30 \mathrm{~mL}$ of acetylcysteine in $30 \mathrm{~mL}$ of saline solution) for chemical dissolution of gastric bezoars. ${ }^{14}$ Endoscopic management can be done by fragmenting the bezoar with water jet, direct suction through a large channel $(6 \mathrm{~mm})$ endoscope, forceps, or snares. Resulting fragments can then be cleared with the endoscope or by using a large bore nasogastric tube (eg, Ewald tube), or allowed to pass through the gastrointestinal tract. ${ }^{12}$ In one study, nine patients treated with adjunctive Metoclopramide (10 mg orally before meals and at bedtime) required a mean of 1.2 courses of endoscopic therapy, while 15 patients treated with endoscopic therapy alone required 1.9 courses of treatment. 15 Surgical management is required in patients who fail chemical dissolution and endoscopic therapy and for patients with complications including obstruction and significant bleeding. If a gastrotomy or enterotomy is performed to remove bezoars, the remainder of the small bowel and stomach should be examined to exclude other retained bezoars. ${ }^{16}$

\section{REFERENCES}

1. Kadian RS, Rose JF, Mann NS. Gastric bezoars--spontaneous resolution. The American Journal of Gastroenterology. 1978;70(1):79-82.

2. DeBakey M, Oshner A. Bezoars and concretions. Surgery. 1938;4:934.

3. Prisant LM, Carr AA, Bottini PB, Kaesemeyer WH. Nifedipine GITS (gastrointestinal therapeutic system) bezoar. Archives of Internal Medicine. 1991;151(9):1868-9. https://doi.org/10.1001/archinte.1991.00400090140025

4. Robles R, Parrilla P, Escamilla C, Lujan JA, Torralba JA, Liron R, et al. Gastrointestinal bezoars. The British Journal of Surgery. 1994;81(7):1000-1.

5. Stack PE, Thomas E. Pharmacobezoar: an evolving new entity. Digestive Diseases. 1995;13(6):356-64. https://doi.org/10.1159/000171515

6. Lee J. Bezoars and foreign bodies of the stomach. Gastrointestinal Endoscopy Clinics of North America. 1996;6(3):605-19.

7. Webb WA. Management of foreign bodies of the upper gastrointestinal tract: Update. Gastrointestinal Endoscopy. 1995;41:39-51. https://doi.org/10.1016/S0016-5107(95)70274-1

8. Andrus $\mathrm{CH}$, Ponsky JL. Bezoars: Classification, pathophysiology, and treatment. American Journal of Gastroenterology. 1988;83:476-8. 
9. Diettrich NA, Gau FC. Postgastrectomy phytobezoars--endoscopic diagnosis and treatment. Archives of Surgery. 1985;120(4):432-5.

https://doi.org/10.1001/archsurg.1985.01390280026006

10. Ladas SD, Kamberoglou D, Karamanolis G, Vlachogiannakos J, Zouboulis-Vafiadis I. Systematic review: Coca-Cola can effectively dissolve gastric phytobezoars as a first-line treatment. Alimentary Pharmacology \& Therapeutics. 2013;37(2):169-73.

https://doi.org/10.1111/apt.12141

11. Holloway WD, Lee SP, Nicholson GI. The composition and dissolution of phytobezoars. Archives of Pathology \& Laboratory Medicine. 1980;104(3):159-61.

12. Zarling EJ, Thompson LE. Nonpersimmon gastric phytobezoar. A benign recurrent condition. Archives of Internal Medicine. 1984;144(5):959-61. https://doi.org/10.1001/archinte.1984.00350170097019

13. Walker-Renard P. Update on the medicinal management of phytobezoars. The American Journal of Gastroenterology. 1993;88(10):1663-6.

14. Silva FG, Goncalves C, Vasconcelos H, Cotrim I. Endoscopic and enzymatic treatment of gastric bezoar with acetylcysteine. Endoscopy. 2002;34(10):845.

https://doi.org/10.1055/s-2002-34265

15. Winkler WP, Saleh J. Metoclopramide in the treatment of gastric bezoars. The American Journal of Gastroenterology. 1983;78(7):403-5.

16. Chintamani, Durkhure R, Singh JP, Singhal V. Cotton Bezoar--a rare cause of intestinal obstruction: case report. BMC Surgery. 2003;3:5.

https://doi.org/10.1186/1471-2482-3-5 